\title{
ANALISA DAN SIMULASI SISTEM PENGENDALIAN MOTOR DC
}

\author{
Anthoinete P.Y.Waroh ${ }^{1)}$ \\ ${ }^{1)} J u r u s a n$ Teknik Elektro Politeknik Negeri Manado \\ e-mail: anthoinete.waroh@gmail.com
}

\begin{abstract}
ABSTRAK
Motor DC merupakan salah satu motor listrik yang banyak digunakan dalam industri dan akan tetap diminati oleh dunia usaha/industri karena karakteristik pengaturannya yang baik. Dari setiap spesifikasi motor DC dapat diamati bentuk karakteristik yang diperoleh dengan menjalankan/mensimulasikan model dinamis matematis dari motor DC. Salah satu tujuan penelitian ini yaitu untuk merumuskan model matematik motor DC kemudian dari model tersebut kemudian dilakukan analisis dan simulasi menggunakan Simulink untuk mempelajari /mengamati pengendalian arus jangkar melalui kendali jangkar, kendali medan maupun melalui kedua terminal tersebut. Manfaat pragmatis yaitu pengetahuan mengenai mengenai karakteristik motor DC untuk setiap jenis spesifikasi. Dari respon karakteristik yang dihasilkan akan membantu untuk menentukan jenis spesifikasi yang cocok digunakan sesuai dengan kebutuhan.
\end{abstract}

Kata kunci : Motor DC, Karakteristik, Simulasi.

\section{ANALYSIS AND SIMULATION OF DC MOTOR CONTROL SYSTEM}

\begin{abstract}
DC motor many used in the industry and should be need by businesses / industries because of the controll characteristics is the best of other DC motor. The specification dc motor can obeserved a characterristic with running / simulation dynamic mathematical model of dc motor. One purpose of this research is the model for get the model of simulation using simulink for observation retstraint armature flows through the control of armature, field control and by the second terminal. Benefit of the aplication of knowledge about the characteristics of dc motor for any type of specification. From the characteristic of the response dc motor. It help determine the kind of specification for Matched used in accordance with the needs.
\end{abstract}

Keywords : DC Motor, characteristics, simulation.

\section{PENDAHULUAN}

Motor dc memerlukan suplai tegangan yang searah pada kumparan medan untuk diubah menjadi energi mekanik. Kumparan medan pada motor dc disebut stator (bagian yang tidak berputar) dan kumparan jangkar disebut rotor (bagian yang berputar). Jika terjadi putaran pada kumparan jangkar dalam medan magnet maka akan timbul tegangan (GGL) yang berubah - ubah arah pada setiap setengah putaran, sehingga merupakan tegangan bolak - balik. Prinsip kerja dari motor dc adalah bahwa arah medan magnet rotor selalu berusaha berada pada posisi yang berlawanan arah dengan arah medan magnet stator. Ini mengikuti sifat magnet bahwa jika magnet yang berlawanan arah didekatkan satu sama lain mereka akan saling tarik - menarik. Magnet yang searah akan saling tolak - menolak. Pada motor dc, daerah kumparan medan yang dialiri arus listrik akan menghasilkan medan magnet yang melingkupi kumparanjangkar dengan arah tertentu. Konversi dari energi listrik menjadi energi mekanik (motor)maupun sebaliknya berlangsung melalui medan magnet. Dengan demikian medan magnet disini selain berfungsi sebagai tempat untuk menyimpan energi, sekaligus sebagai tempat berlangsungnya perubahan energi. Agar proses perubahan energi dapat berlangsung secara sempurna, maka tegangan sumber harus lebih besar dari ada tegangan gerak yang disebabkan reaksi lawan. Untuk menjaga kontinuitas momen putar rotor maka 
arah medan magnet rotor harus menyesuaikan. Efek perubahan arah medan rotor dapat diciptakan dengan melakukan perubahan arah aliran arus yang mengalir dalam rangkaian jangkar. Perubahan aliran arus rotor ini dilakukan dengan menghubungkan rangkaian jangkar dengan sumber tegangan luar melalui sikat (brush) yang dilengkapi dengan komutator.

\section{TINJAUAN PUSTAKA}

Motor didefinisikan sebagai alat yang dapat mengubah energi listrik menjadi torsi (momen putar) karena adanya arus yang mengalir pada belitan jangkar. Oleh katena itu motor dapat dimodelkan dengan bagan kotak berikut :

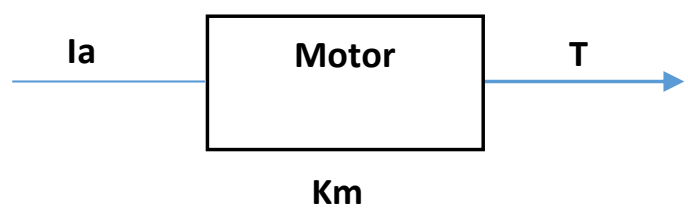

Gambar 1. Konversi energi pada motor listrik

Model fisik dari motor dc secara lengkap yang menggambarkan bagian elektrik dan mekanik :

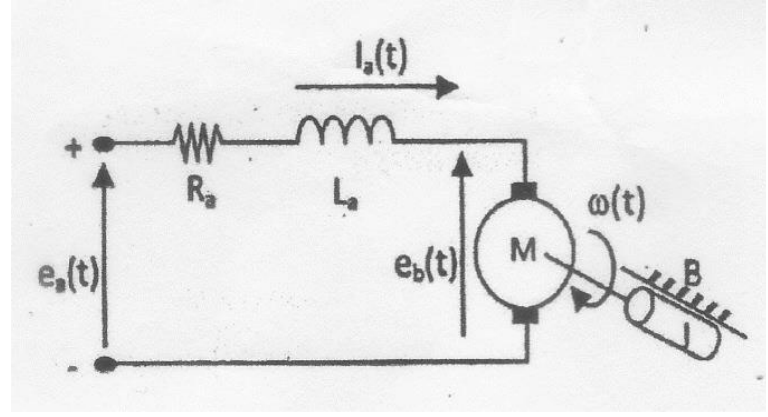

Gambar 2. Model fisik motor dc

Model dinamik matematika motor dc dapat diperoleh dari model fisiknya, sebagai berikut :

a. Bagian elektrik:

$$
e_{a}(t)-e_{b}(t)=L_{a} \frac{d i_{a}(t)}{d t}+R_{a} I_{a}(t)
$$

b. Bagian Mekanik

$$
\begin{aligned}
& e_{a}(t)-e_{b}(t)=L_{a} \frac{d i_{a}(t)}{d t}+R_{a} I_{a}(t) \\
& T(t)=J \frac{d \omega(t)}{d t}+B \omega(t)
\end{aligned}
$$
c. Sifat Motor : $T(t)=K_{m} i_{a}(t)$
d. Sifat Generator : $e_{b}(t)=k_{b} \omega(t)$

Persamaan-persamaan tersebut diatas digunakan untuk meperoleh model fungsi alih motor.

Model fungsi alih yang umum untuk motor dc ialah sebagai berikut :

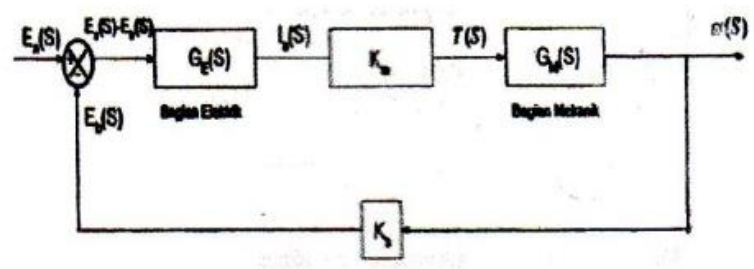

Gambar 3. Model Fungsi Alih Motor dc

$$
\begin{aligned}
& G_{E}(s)=\frac{I_{a}(s)}{E_{a}(s)-E_{b}(s)}=\frac{1}{L_{a} s-R_{a}} \\
& G_{M}(s)=\frac{\omega(s)}{T(s)}=\frac{1}{J s+B}
\end{aligned}
$$

Kecepatan motor dc terkendali jangkar, dikendalikan oleh tegangan jangkar ea :

$L_{a}\left(\frac{d i_{a}}{d t}\right)+R_{a} I_{a}(t)+\mathrm{eb}(\mathrm{t})=$ ea $(\mathrm{t})$

Arus jangkar menghasilkan torsi yang dikenakan pada momen inersia dan gesekan sehingga ;

$J\left(\frac{d^{2} \theta}{d t^{2}}\right)+B\left(\frac{d \theta}{d t}\right)=T=K_{m} I_{a}(t) \ldots$

$J\left(\frac{d \omega}{d t}\right)+B \omega(t)=T_{m}=K_{m} I_{a}(t)$.

Bentuk Laplace dari persamaan (1) adalah :

$\left(L_{a} s+R_{a}\right) I_{a}(s)+E \mathrm{~b}(\mathrm{~s})=\mathrm{Ea}(\mathrm{s})$

Atau $\left(I_{a} s=\frac{\left(E_{a}(s)-K_{b} \omega(s)\right)}{\left(L_{a} s+R_{a}\right)}\right.$

Persamaan (5) dimasukkan ke persamaan (1) sehingga persamaan (3) dapat dinyatakan sebagai berikut :

$$
\begin{aligned}
(J s+B) \omega(s) & =\left(\mathrm{K}_{\mathrm{m}} \text { Ea }(\mathrm{s})\right. \\
& \left.-\mathrm{K}_{\mathrm{b}} \omega(\mathrm{s})\right) /\left(\mathrm{L}_{\mathrm{a}} \mathrm{s}+\mathrm{R}_{\mathrm{a}}\right)
\end{aligned}
$$

Mengalikan setiap ruas dengan $\left(L_{a} s+R_{a}\right)$ sehingga :

$$
\begin{aligned}
(J s+B)\left(\mathrm{L}_{\mathrm{a}} \mathrm{s}\right. & \left.+\mathrm{R}_{\mathrm{a}}\right) \omega(\mathrm{s}) \\
& =\left(\mathrm{K}_{\mathrm{m}} \operatorname{Ea}(\mathrm{s})\right. \\
& \left.-\mathrm{Km} \mathrm{K}_{\mathrm{b}} \omega(\mathrm{s})\right)
\end{aligned}
$$

Dengan demikian :

$$
\begin{aligned}
\omega(s)=\left(\mathrm{K}_{\mathrm{m}} \mathrm{Ea}\right. & (\mathrm{s}) \\
& /(\mathrm{Js}+B)\left(\mathrm{L}_{\mathrm{a}} \mathrm{s}+\mathrm{R}_{\mathrm{a}}\right) \\
& \left.+\mathrm{Km} \mathrm{K}_{\mathrm{b}}\right)
\end{aligned}
$$

Sehingga bentuk model matematika motor dc kendali jangkar menjadi : 
$\omega_{m}(s)=\frac{K_{m} E a(s)}{s^{2}+\left(\frac{B L_{a}+R_{a} J}{L_{a} J}\right) s+\left(B R_{a}+K m K_{b}\right) /\left(L_{a} J\right)}$

Persamaan (6) memiliki bentuk yang identik dengan persamaan transformasi Laplace

$F(s)=\frac{\omega_{\mathrm{n}}^{2}}{\mathrm{~s}\left(\mathrm{~s}^{2}+2 \omega_{\mathrm{n}} \xi \mathrm{s}+\omega_{\mathrm{n}}^{2}\right)} \quad$ jika masukan yang diberikan merupakan fungsi step.

Bentuk fungsi t dinyatakan dengan

$f(t)=1-$

$\left[\left(\frac{1}{\sqrt{1-\xi^{2}}}\right) \mathrm{e}^{-\mathrm{t}} \xi \omega_{\mathrm{n}} \sin \left(\left(\omega_{\mathrm{n}}(\sqrt{1-\xi)}) \mathrm{t}\right.\right.\right.$

$$
+\theta)]
$$

Dimana : $\theta=\cos ^{-1} \xi$. Secara umum bentuk persamaan diatas dinyatakan dalam bentuk :

$\omega_{m}(s)=\frac{\mathrm{K}_{\mathrm{o}} \mathrm{Ea}(\mathrm{s})}{\left(\mathrm{s}^{2}+2 \omega_{\mathrm{n}} \xi \mathrm{s}+\omega_{\mathrm{n}}^{2}\right)}$

dimana $\mathrm{Ko}=\mathrm{K} /(\mathrm{La} \mathrm{J})$

$\frac{\left(B L_{u}+R_{u} J\right)}{L_{a} J}=2 \omega_{n} \xi$

$\frac{\left(B R_{a}+K K_{b}\right)}{L_{a} J}=\omega_{n}^{2}$

$\omega_{d}=\omega_{n}\left(\sqrt{1-\xi^{2}}\right), \theta=\cos ^{-1} \xi$ dimana $\theta$ dinyatakan dalam radian.

Torka $\mathrm{T}$ yang dihasilkan motor berbanding lurus dengan hasil kali $I_{a}$ dan fluks magnet pada celah udara $\Psi=K_{f} i_{f}$ dimana $K_{f}$ adalah konstanta. Dengan demikian $\mathrm{T}$ dinyatakan dalam bentuk :

$T_{m}(t)=K_{f} I_{f}(t) K_{t} I_{a}(t)$

$T_{m}(t)=K I_{f}(t)$

Dimana $\mathrm{K}$ adalah konstanta torka motor, $I_{a}(t)$ konstan. Ini merupakan suatu sifat motor dimana torka yang dihasilkan dari arus. Persamaan untuk sistem dinyatakan dengan :

$E_{i}(s)=\left(L_{f} s+R_{f}\right) I_{f}(s)$

(kondisi awal=0) $I_{f}(s)=\left(E_{f}(s) /\left(L_{f} s+R_{f}\right)\right.$

$I_{f}(s)=\left(\frac{E_{f}(s)}{L_{f}}\right) /\left(s+R_{f} / L_{f}\right)$

Hubungan torka terhadap kecepatan motor dinyatakan dengan :

$$
\begin{aligned}
& T_{m}(s)=J_{T} \omega_{m}(s) s+B_{T} \omega_{m}(s) \\
& T_{m}(s)=\left(J_{T} s+B_{T}\right) \omega_{m}(s)
\end{aligned}
$$

$$
\omega_{m}(s)=\left(\frac{T_{m}(s)}{J_{T}}\right) /\left(s+\left(\frac{B_{T}}{J_{T}}\right)\right)
$$

Masukkan persamaan (9) ke (7) kemudian ke (10) diperoleh model matematik motor dc kendali medan $\left(I_{a}\right.$ konstan).

$\omega_{m}(s)=\frac{K\left(\frac{E_{f}(s)}{J_{T} L_{f}}\right)}{\left(s+\left(\frac{B_{T}}{J_{T}}\right)\right)\left(s+\frac{R_{f}}{L_{f}}\right)}$.

Jika masukan berupa step function maka persamaan diatas menjadi :

$\omega_{m}(s)=\frac{K\left(\frac{E_{f}(s)}{J_{T} L_{f}}\right)}{\left(s+\left(\frac{B_{T}}{J_{T}}\right)\right)\left(s+\frac{R_{f}}{L_{f}}\right)}$ bentuk fungsi invers dari persamaan ini adalah :

$$
\begin{aligned}
& \omega_{m}(t)=\frac{K\left(\frac{E_{f}(s)}{J_{T} L_{f}}\right)}{\left(\frac{B_{T}}{J_{T}}\right)\left(\frac{R_{f}}{L_{f}}\right)}\left[1+\frac{1}{\left(\frac{B_{T}}{J_{T}}\right)\left(\frac{R_{f}}{L_{f}}\right)}\left(\left(\frac{B_{T}}{J_{T}}\right) e^{\frac{-t R_{f}}{L_{f}}}-\right.\right. \\
& \left.\left(\frac{R_{f}}{L_{f}}\right) e^{\frac{-t B_{f}}{J_{T}}}\right] \ldots \ldots \ldots(12)
\end{aligned}
$$

Persamaan (11) diberi masukan fungsi step sehingga persamaan identik dengan

$F(s)=\frac{\omega_{n}^{2}}{s\left(s^{2}+2 \omega_{n} \xi s+\omega_{n}^{2}\right)}$ secara umum bentuk persamaan diatas dinyatakan dalam bentuk

$\omega(s)=\frac{K_{0} B_{T}(s)}{\left(s^{2}+2 \omega_{n} \xi s+\omega_{n}^{2}\right)} \operatorname{dimana} K_{0}=\frac{K}{J_{T} L_{f}}$

$\frac{\left(B_{T} L_{f}+R_{a} J_{T}\right.}{\left(L_{f} J_{T}\right)}=2 \omega_{n} \xi$

$\frac{\left(B_{T} R_{f}\right)}{L_{f} J_{T}}=\omega_{n}^{2}$

\section{HASIL DAN PEMBAHASAN}

Data yang digunakan dalam analisa dan simulasi pada penelitian ini berdasarkan data motor yang diperoleh dari U.S. Electrical Motors Division of Emerson Electric Co. sebagai berikut :

\section{Analisa motor de dengan kendali jangkar ( $I_{f}$ konstan) :}

$$
\begin{aligned}
& P=60 \mathrm{HP} \\
& \omega_{\text {nominal }}=2500 \mathrm{rpm} \\
& P=60 \mathrm{HP}=44760 \mathrm{Watt} \\
& \omega_{\text {nominal }}=2500 \cdot \frac{2 \pi}{60}=261,67 \mathrm{rad} / \mathrm{det} \\
& T_{\text {nominal }}=\frac{P}{\omega}=171,06 \mathrm{~N} \cdot \mathrm{m} \\
& B=\frac{T}{\omega}=0,654 \mathrm{Nm} \mathrm{det} / \mathrm{rad}
\end{aligned}
$$


$J=5 L b F t^{2}=0,211 \mathrm{~kg} \cdot \mathrm{m}^{2}$

$R_{a}=0,19 \mathrm{ohm} ; R_{f}=113 \mathrm{ohm} ;$

$E a_{\text {nom }}=500 \mathrm{~V}$

$L a=0.005 H ; L f=0,187 \mathrm{H} ;$ Ia $n o m=99 \mathrm{~A}$

Pada kondisi static dimana kondisi awal $=0$ maka :

$\frac{d i_{f}}{d t}=\frac{E_{f}}{L_{f}}-I_{f} \frac{R_{f}}{L_{f}} ; I_{f}=\frac{E_{f}}{R_{f}}=\frac{300}{113}=2,655 \mathrm{~A}$

Menentukan nilai konstanta melalui bentuk persamaan torsi :

$T_{m}=K_{m} I_{a}$

$K_{m}=1,73 \mathrm{Nm} \mathrm{det} / \mathrm{rad}$

Menghitung konstanta motor :

$K_{b}=\left(e_{a}(t)-\frac{R_{a} I_{a}(t)}{\omega(t)}=1.84 \mathrm{~V} . \mathrm{det} / \mathrm{rad}\right.$

$K_{o}=\frac{K_{m}}{L_{a} J}=\frac{1,73}{0,005.0,211}=1638 \mathrm{~N} / \mathrm{AH} \mathrm{kgm}$

$\frac{\left(B L_{a}+R_{a} J\right)}{L_{a} J}=41,098$

$\frac{B R_{a}+K_{m} K_{b}}{L_{a} J}=3129,48$

Tegangan masukan adalah unit step function maka :

$\omega(s)=\frac{1638}{s\left(s^{2}+41,098 s+3129,48\right)}$

Secara umum persamaan dapat dinyatakan dalam bentuk

$\omega(s)=\frac{K_{0} E_{2}(s)}{\left(s^{2}+2 \omega_{n} \xi+\omega_{n}^{2}\right)} \operatorname{dimana} K_{o}=\frac{K}{L_{a} J}$

$\omega_{n}^{2}=3129,48 \quad$ sehingga $\quad \omega_{n}=55,94 \quad ;$ $2 \omega_{n} \xi=41,098$ maka $\xi=0,3673$ (redaman kurang) respon berosilasi sehingga :

$\omega(t)=261679[1-$

$\left(1,07 e^{-20,55 t} \sin (52,03 t+0,38 \pi)\right)$

$\omega(t)$ nominal $=261,67 \mathrm{rad} /$ det $\quad$ (sesuai data motor)

$$
\begin{aligned}
& I_{a}(s)=(s+a) k_{1} /\left(s^{2}+2 \omega_{n} \xi+\omega_{n}^{2}\right) \\
& I_{a}(s)=200 \cdot \frac{500(s+3,1)}{s\left(s^{2}+41.098 s+3129,48\right)}
\end{aligned}
$$

bentuk invers laplacenya :

$$
\begin{aligned}
& I_{a}(t)=1921,97 e^{-20,55 t} \sin 52,03 t+ \\
& 99\left(1-1,07 e^{-20,55 t} \sin (52,03 t+0,38 \pi)\right)
\end{aligned}
$$

\section{$I_{a}(t)$ nominal $=99 \mathrm{~A}$ (sesuai data motor)}

Persamaan diatas memiliki nilai maksimum pada kondisi $\frac{d I_{a}}{d t}=0$

Yang terjadi pada $t_{p}=0,024$ detik $I_{a} \max =1174 \mathrm{~A}$

\section{Simulasi Motor de dengan kendali jangkar (If konstan) :}

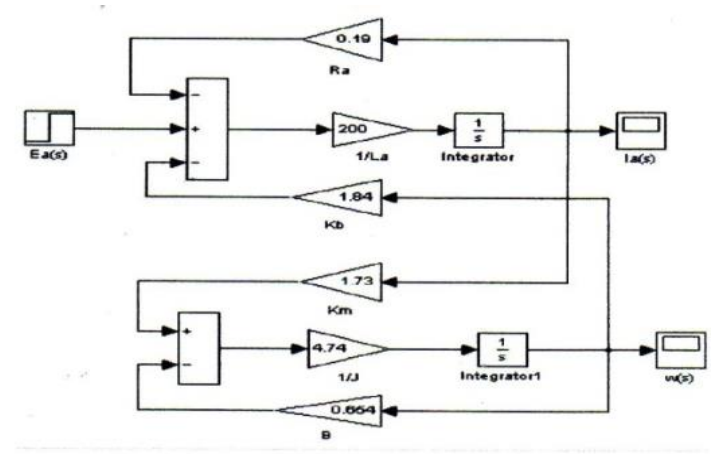

Gambar 4. Diagram Blok Simulasi motor dc kendali jangkar

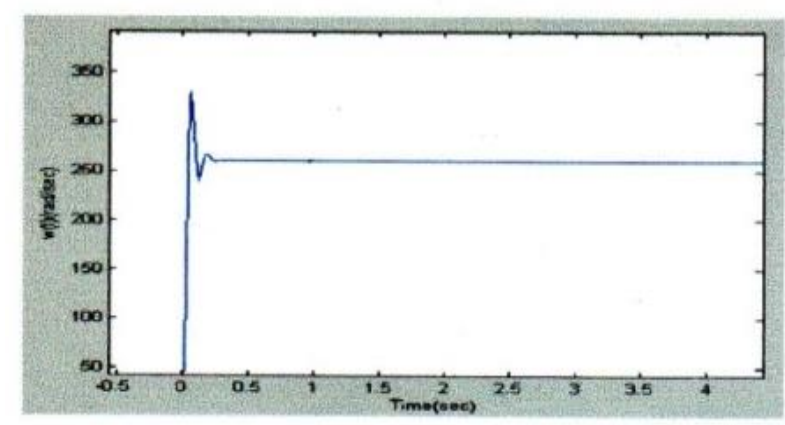

Gambar 5. Hasil Simulasi motor dc kendali jangkar (Ia Vs t)

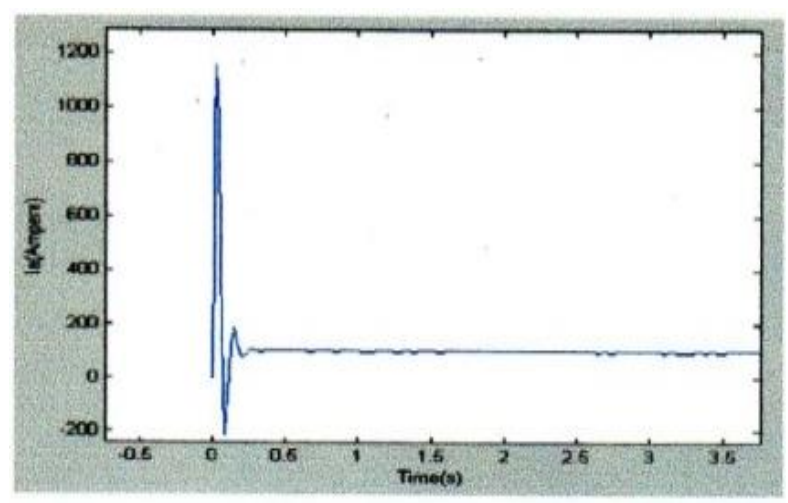

Gambar 6. Hasil Simulasi motor dc kendali jangkar $(\omega$ Vs t $)$ 
Analisa motor de dengan kendali medan ( Ia konstan ) :

$\mathrm{P}=60 \mathrm{~Hz}$

$\omega_{\text {nominal }}=2500 \mathrm{rpm}$

$\mathrm{P}=60.746 \mathrm{Watt}=44760 \mathrm{Watt}$

$\omega_{\text {nominal }}=2500 \cdot \frac{2 \pi}{60}=261,67 \mathrm{rad} / \mathrm{det}$

$\mathrm{T}_{\text {nominal }}=\mathrm{P} / \omega=171,06 \mathrm{~N} \cdot \mathrm{m}$

$\mathrm{B}=\mathrm{T} / \omega=0,654 \mathrm{Nm} \operatorname{det} / \mathrm{rad} ; \mathrm{J}=5 \mathrm{Lb} \mathrm{Ft}^{2}=$ $0,211 \mathrm{Kg} \mathrm{m}^{2}$

$\mathrm{Ra}=0,19 \mathrm{ohm}, \mathrm{Rf}=113 \mathrm{Ohm} ; \mathrm{Ea}_{\text {nom }}=500 \mathrm{~V}$ $\mathrm{La}=0,005 \mathrm{H} ; \mathrm{Lf}=0,187 \mathrm{H}$; Ia ${ }_{\text {nom }}=99 \mathrm{~A} ; \mathrm{Ef}$ $=300 \mathrm{~V}$ ( Step function)

Pada kondisi statik dimana kondisi awal $=0$, maka :

$\frac{\mathrm{di}_{\mathrm{f}}}{\mathrm{dt}}=\frac{\mathrm{E}_{\mathrm{f}}}{\mathrm{L}_{\mathrm{f}}}-\mathrm{i}_{\mathrm{f}} \frac{\mathrm{R}_{\mathrm{f}}}{\mathrm{L}_{\mathrm{f}}} \quad ; \quad$ If $=\mathrm{Ef} / \mathrm{Rf}=300 / 113=$ $2,655 \mathrm{~A}$

Menentukan nilai konstanta melalui bentuk persamaan torsi :

$\mathrm{Tm}=\mathrm{K}$. If $\mathrm{K}=64,4 \mathrm{Nmdet} / \mathrm{rad}$.

$\left(K .\left(E_{f}(s)\right) /\left(J_{T} \cdot L_{f}\right)=491331\right.$

$\left(B_{T} L_{f}+R_{a} J_{T}\right) /\left(J_{T} \cdot L_{f}\right)=2 \omega_{n} \xi=606$

$($ BT. RF $) /($ Lf. JT $)=\omega^{2}=1878 ; \omega n=43$

Dimana $\xi=7 ; \quad \xi>1 \quad$ (redaman lebih)

$\omega_{\mathrm{m}}(\mathrm{s})=491331 / \mathrm{s}\left(\mathrm{s}^{2}+606 \mathrm{~s}+1878\right)$ $\mathrm{rad} / \mathrm{det}$

$\omega_{m}(t)=262\left[1+0,0017\left((3,098) \mathrm{e}^{-606 t}-\right.\right.$ (606) $\left.\left.\mathrm{e}^{-3,098 \mathrm{t}}\right)\right] \mathrm{rad} / \mathrm{det}$

Pada kondisi $\mathrm{t} \gg$ > maka $\omega_{m}(t)=262$ $\mathrm{rad} / \mathrm{det}$

Besar arus medan dinyatakan dengan :

If $(s)=(\mathrm{Ef} / \mathrm{Lf}) /(\mathrm{s}+\mathrm{Rf} / \mathrm{Lf})$

Jika Ef dnyatakan dengan masukan fungsi step maka :

If $(s)=(E f / L f) / s(s+R f / L f) \quad A$.

$\operatorname{If}(t)=\operatorname{Ef} / \operatorname{Rf}\left(1-e^{-(\operatorname{Rf} / L f) \cdot t}\right)=2,65\left(1-e^{-606,1 t}\right.$ ) A.

Simulasi Motor de dengan kendali Medan ( Ia konstan ) :

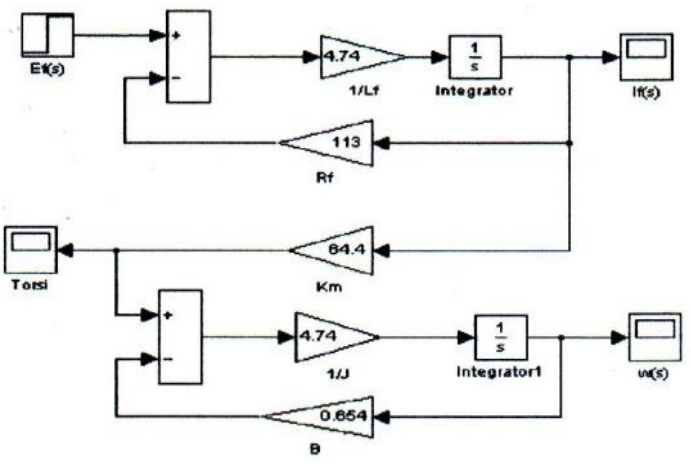

Gambar 7. Diagram Blok Simulasi motor dc kendali Medan

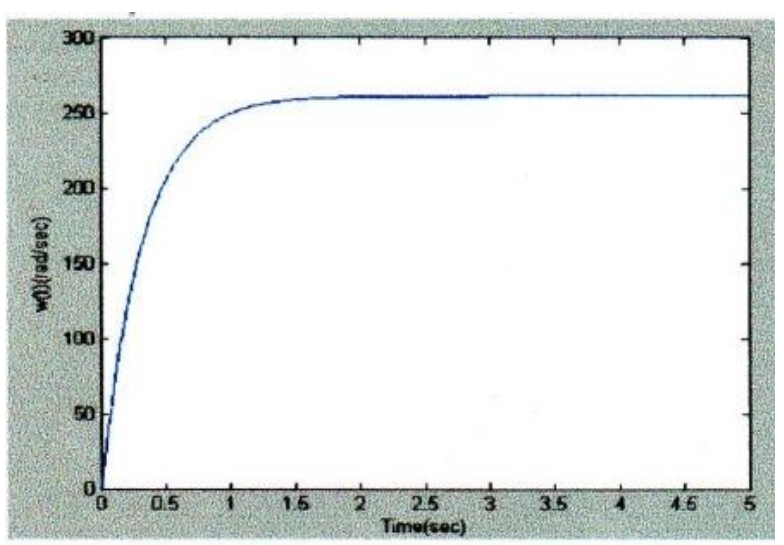

Gambar 8. Hasil Simulasi motor dc kendali medan (If Vs $\mathrm{t}$ )

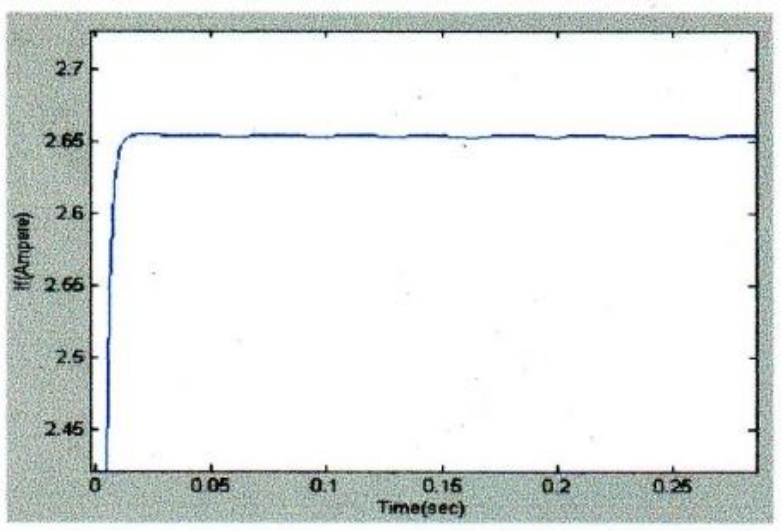

Gambar 9. Hasil Simulasi motor dc kendali medan ( $\omega$ Vst $)$

\section{Motor dc dengan If dan Ia berubah}

Pada pnelitian ini digunakan model simulasi sesuai dengan rangkaian blok diagram gambar di bawah ini :

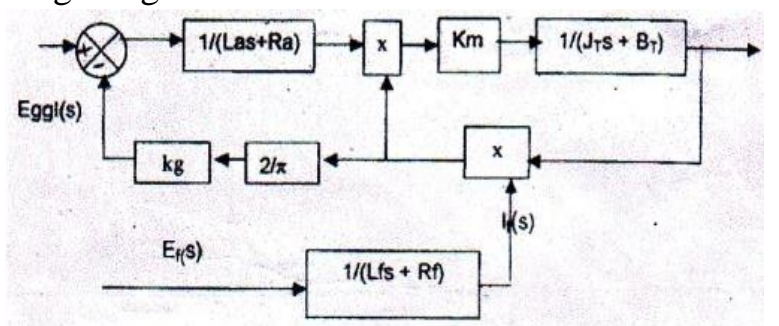

Gambar 10. Blok diagram motor dc penguatan terpisah

Data yang digunakan dalam analisa dan simulasi pada penelitian ini berdasarkan data motor yang kami peroleh dari U.S. Electrical motors Division Of Emerson Electric Co. sebagai berikut :

$\mathrm{P}=60 \mathrm{~Hz}$

$\omega_{\text {nominal }}=2500 \mathrm{rpm}$ 
$\mathrm{P}=60.746 \mathrm{Watt}=44760 \mathrm{Watt}$

$\omega_{\text {nominal }}=2500 \cdot \frac{2 \pi}{60}=261,67 \mathrm{rad} / \mathrm{det}$

$\mathrm{T}_{\text {nominal }}=\mathrm{P} / \omega=171,06 \mathrm{~N} \cdot \mathrm{m}$

$\mathrm{B}=\mathrm{T} / \omega=0,654 \mathrm{Nm} \operatorname{det} / \mathrm{rad} ; \mathrm{J}=5 \mathrm{Lb} \mathrm{Ft}^{2}=$ $0,211 \mathrm{Kg} \mathrm{m}^{2}$

$\mathrm{Ra}=0,19 \mathrm{Ohm}, \mathrm{Rf}=113 \mathrm{Ohm} ; \mathrm{Ea}_{\text {nom }}=500 \mathrm{~V}$ $\mathrm{La}=0,005 \mathrm{H} ; \mathrm{Lf}=0,187 \mathrm{H}$; Ia nom $=99 \mathrm{~A}$.

Pada kondisi statik dimana kondisi awal $=0$, maka :

$\frac{d_{f}}{d t}=\frac{E_{f}}{L_{f}}-i_{f} \frac{R_{f}}{L_{f}} ;$ If $=E f / R f=300 / 113=2,655 \mathrm{~A}$ Menentukan nilai konstanta melalui bentuk persamaan torsi :

$\mathrm{Tm}=\mathrm{K}$. If. Ia

$\mathrm{Km}=\mathrm{Tm} /($ If . Ia $)=171,06 /(92,65$ X 99) $=0,651 \mathrm{Nm} / \mathrm{A}^{2}$.

$\mathrm{Ea}(\mathrm{t})-2 \mathrm{Kg}$ If $\omega / \pi=\mathrm{La} \mathrm{di}_{\mathrm{a}}(\mathrm{t}) / \mathrm{dt}+\mathrm{Ra}$. Ia (t) ; $\mathrm{Kg}=1,087 \mathrm{~V}$ det $/ \mathrm{A} \mathrm{rad}$

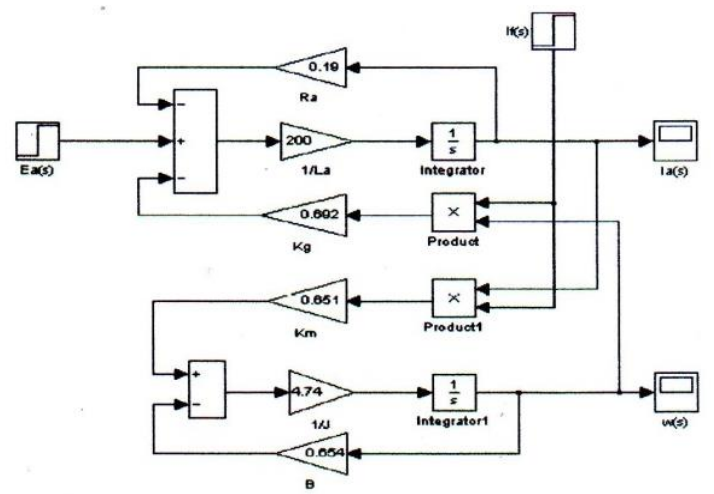

Gambar 11. Diagram Blok Simulasi motor dc dengan Ia berubah dan asumsi If konstan

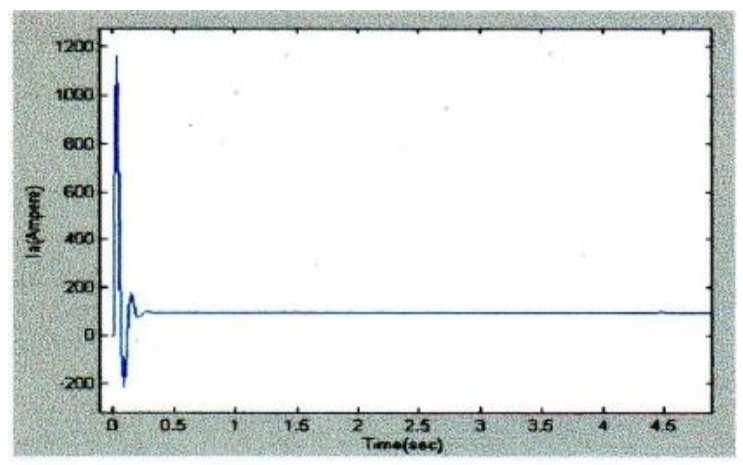

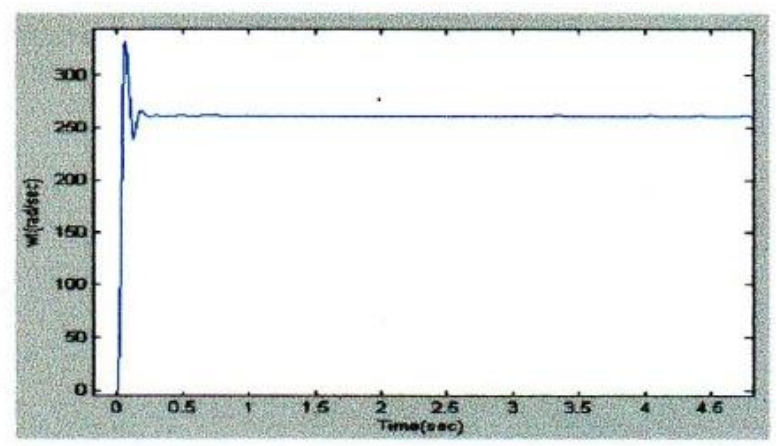

Gambar 13. Hasil Simulasi kendali motor dc dengan Ia berubah dan asumsi If konstan $(\omega \mathrm{Vs} t)$

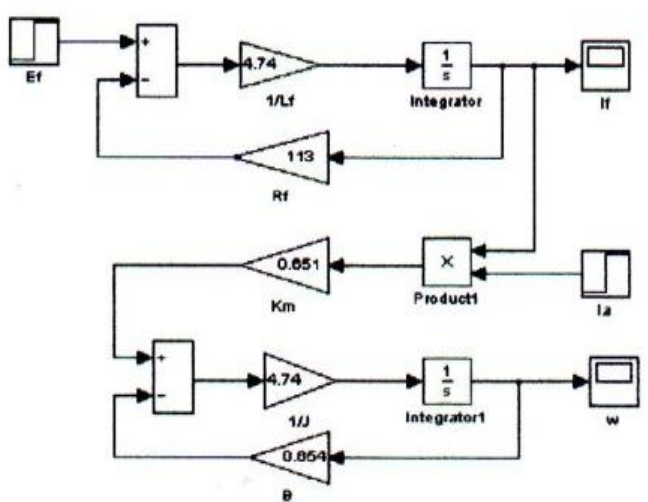

Gambar 14. Diagram Blok Simulasi motor dedengan If berubah dan asumsi Ia konstan

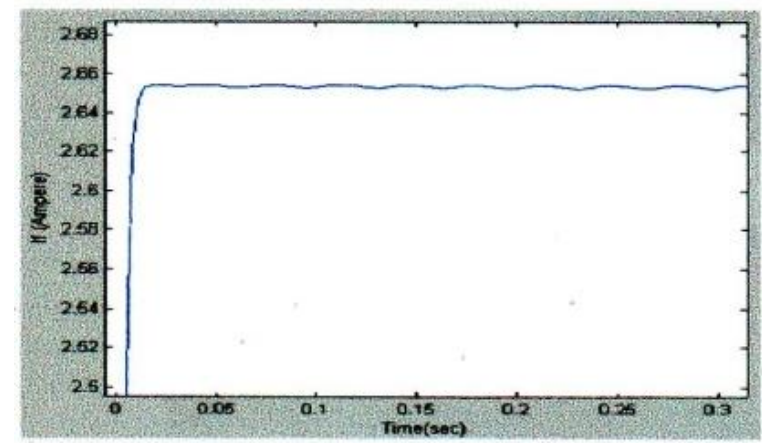

Gambar 15. Hasil Simulasi kendali motor dc dengan If berubah dan asumsi ia konstan ( If $\mathrm{Vs} \mathrm{t}$ )

Gambar 12. Hasil Simulasi kendali motor dc dengan Ia berubah dan asumsi If konstan (If Vs t) 


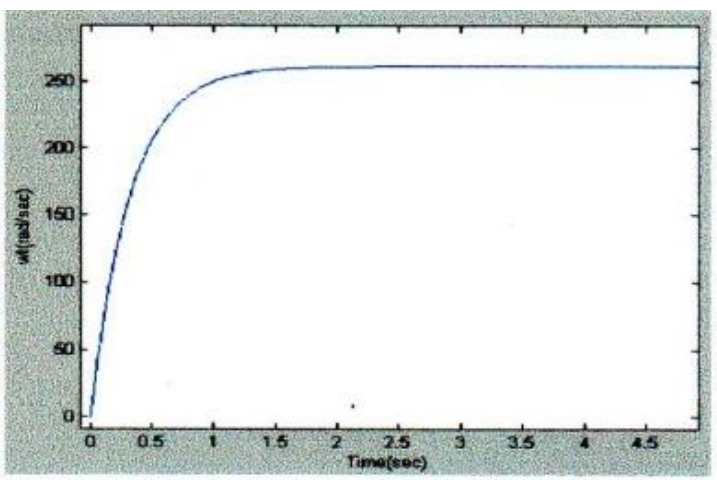

Gambar 16. Hasil Simulasi kendali motor dc dengan If berubah dan asumsi Ia konstan ( $\omega$ Vs t )

Hasil arus jangkar (Ia), arus medan (If) dan Kecepatan motor $(\omega)$ yang diperoleh dari simulasi dengan simulink ternyata hasilnya sama dengan yang diperoleh secara analitis.

\section{KESIMPULAN}

1. Pada analsa motor dc maka hasil yang diperoleh berupa besar arus jangkar, besar arus medan dan kecepatan motor dc secara analitik ternyata hasilnya sama dengan hasil yang diperoleh dengan cara silumlasi dengan menggunakan simulink.

2. Sistem pengaturan motor dc dalam penelitian ini diawali dengan mengembangkan persamaan dasar dan hubungan elektromagnetis yang mengatur kelakuan dan karakteristik motor dc.

3. Model yang telah ditampilkan dalam penelitian ini dapat dipakai untuk mempelajari kelakuan / karakteristik motor dc atau motor jenis lainnya. Hal ini dilakukan dengan mengganti variabel / parameter yang digunakan pada penelitian ini.

4. Penelitian ini menghasilkan model motor dc, dimana dari model tersebut dapat diganti nilai parameternya sesuai dengan spesifikasi motor dan dari setiap spesifikasi motor dc tersebut maka dapat diamati bentuk karakteristik /sifat dari setiap spesifikasi motor $\mathrm{dc}$ atau motor jenis apasaja yang dieroleh dengan cara melakukan simulasi menggunakan simulink.

\section{DAFTAR PUSTAKA}

A.E.Fitzgerald,1997,Mesin - mesin Listrik, edisi keempat,Alih Bahasa Ir.Djoko Achyanto,MSc.EE, Penerbit Erlangga, Jakarta.

Chapman,S.J. 1997,Electric Machinery Fundamentals Second Edition, McGrawHill, Singapore.

D’Azzo,J.J. 1966, Feedback Control System Analysis and Synthesis Second Edition, McGraw-Hill Kgakusha Ltd.

Ogata Katsuhiko dan Leksono Edi, 1989, Teknik Kontrol Authomatik, Penerbit Erlangga Jakarta.

S.Pakpahan, 1988, Kontrol Otoma Teori dan Penerapan, Penerbit Erlangga Jakarta. 